\title{
Ovarian Hilus Cell Tumor
}

National Cancer Institute

\section{Source}

National Cancer Institute. Ovarian Hilus Cell Tumor. NCI Thesaurus. Code C4214.

A benign Leydig cell tumor which arises in the hilar area of the ovary. 